\title{
An Existential Function of Enemyship: Evidence That People Attribute Influence to Personal and Political Enemies to Compensate for Threats to Control
}

\author{
Daniel Sullivan, Mark J. Landau, and Zachary K. Rothschild \\ University of Kansas
}

\begin{abstract}
Perceiving oneself as having powerful enemies, although superficially disagreeable, may serve an important psychological function. On the basis of E. Becker's (1969) existential theorizing, the authors argue that people attribute exaggerated influence to enemies as a means of compensating for perceptions of reduced control over their environment. In Study 1, individuals dispositionally low in perceived control responded to a reminder of external hazards by attributing more influence to a personal enemy. In Study 2, a situational threat to control over external hazard strengthened participants' belief in the conspiratorial power of a political enemy. Examining moderators and outcomes of this process, Study 3 showed that participants were especially likely to attribute influence over life events to an enemy when the broader social system appeared disordered, and Study 4 showed that perceiving an ambiguously powerful enemy under conditions of control threat decreased perceptions of external risk and bolstered feelings of personal control.
\end{abstract}

Keywords: enemyship, control, existential psychology, system belief, risk perception

Our psychological construction of enemyship is a triumph, that consists in truly understanding the value of having enemies.

-Nietzsche $(1889 / 1980)$

The psychological functions of friendships and romantic relationships have been extensively examined in the social psychological literature (e.g., Baumeister \& Leary, 1995; Thibaut \& Kelley, 1986). Very little attention, however, has focused on another type of close relationship: enemyship. Some work has examined the possibility that enemy figures and images are instrumental at the group level for increasing ingroup cohesion or justifying collective action (Allport, 1954/1979; Silverstein, 1992); however, this work has not directly examined the psychological significance of enemyships, both political and personal, for the individual. More recently, researchers have begun to examine personal enemyship, defined as a hostile relationship in which one person actively seeks another's downfall (Adams, 2005; Wiseman \& Duck, 1995). However, we are aware of no prior research examining how and why people perceive enemy relations, independent of whether those relations actually exist. To fill this gap, we examined enemyship defined as the perception that another person or group is using influence and power to undermine one's own goals and wellbeing.

Daniel Sullivan, Mark J. Landau, and Zachary K. Rothschild, Department of Psychology, University of Kansas.

We would like to thank Joseph Tennant and Cameron Pestinger for their assistance with data collection. We also thank Pascal Deboeck and Lowell Gaertner for their statistical advice.

Correspondence concerning this article should be addressed to Daniel Sullivan, Department of Psychology, University of Kansas, 1415 Jayhawk Boulevard, Room 426, Lawrence, KS 66045-7556. E-mail: dsully@ku.edu
Enemyship so defined is quite common (Holt, 1989), despite being viewed as paranoid in some cultural contexts (Adams, 2005). In an effort to explain this observation, we propose that perceptions of influential personal and political enemies, however superficially disagreeable, serve an important psychological function for the individual. Drawing on existential and anthropological theories (Becker, 1969; M. Douglas, 1966), we contend that people are motivated to perceive themselves as controlling their environment yet realize that their lives can be negatively affected by myriad diffuse and capricious hazards. To minimize the threat that this realization potentially poses to perceived control, people narrow down the multifarious sources of potential misfortune to a focal individual or group that can be effectively controlled, managed, or (at minimum) understood. Thus, to the extent that an enemy is perceived to be an influential source of misfortune, enemyship allows people to maintain a sense of personal control by perceiving their overall environment as containing less randomly distributed risk.

If this analysis is correct, then people with dispositionally low or situationally reduced perceptions of control over external hazards will compensate by attributing exaggerated influence to an enemy, even when the enemy's influence is not obviously linked to those hazards. As discussed below, a crosscultural perspective (M. Douglas, 1966) suggests that the motivation to attribute influence to an enemy will be especially strong when people view the broader social system as failing to provide protection from harm. Furthermore, perceiving oneself as having an ambiguously or enigmatically powerful enemy should, counterintuitively, lower people's perceptions of risk and bolster feelings of personal control. We tested these hypotheses in four studies, employing diverse methods to assess the relationships among perceptions of personal control, the 
influence of personal and political enemies, and the integrity of the broader social system.

\section{Prior Research on Enemy Perceptions}

Despite the relative dearth of enemyship research (Wiseman \& Duck, 1995), researchers have discovered some interesting patterns in people's perceptions of enemies. For one, enemyship appears to be fairly common. Holt (1989) found that $70 \%$ of North American participants reported having had a personal enemy at some point in their lives (usually coworkers or ex-lovers) and characterized these individuals as actively and intentionally using power to block their goals and inflict harm (see also Wiseman, 1989). Adams (2005) showed evidence of cross-cultural differences in constructions of enemyship: Compared to Ghanaians, North Americans claim to have fewer personal enemies and are also more likely to judge a person who claims to have enemies as paranoid, whereas Ghanaians tend to see such persons as quite rational. Interestingly, people across cultural contexts tend to perceive enemies as having ambiguous power and influence (M. Douglas, 1966). North Americans perceive enemies as having obscure motives and uncanny abilities to undermine their best interests (e.g., by turning others against one; Holt, 1989; Wiseman \& Duck, 1995), while Ghanaians associate enemies with cryptic powers such as sorcery (Adams, 2005).

Taken together, these lines of research suggest that enemyship plays an important role in the social lives of many people across diverse cultural contexts. However, whereas research has illuminated the motives that shape people's perceptions of other types of interpersonal relationships (e.g., friendships), comparatively little is known about the motivational underpinnings of enemyship. While a commonsense perspective might suggest that enemyship is merely the result of paranoia, a more interesting possibility is that perceptions of influential enemies serve a positive psychological function for the individual. In the next section, we introduce a theoretical framework for understanding enemyship's function; we then report four studies that empirically assessed this perspective. We believe this work not only sheds light on enemyship's psychological function but also provides a deeper understanding of the role of situational factors in enemyship and the cross-cultural tendency to view enemies as having ambiguous powers.

\section{The Present Research: An Existential Perspective on Enemyship's Psychological Function}

In his book Angel in Armor, Ernest Becker (1969) argued that people's conviction that life has meaning and the self is valuable is fundamentally based on their perceived ability to effectively negotiate their environment and control their fate. People realize, however, that their well-being and even existence can be dramatically affected by many random sources of misfortune-from stepping on a rusty nail to shifting social alliances-that are impossible to fully anticipate or control. Becker argued that a common strategy people use to compensate for decreased perceptions of personal control is to focalize the many hazards that exist in the world onto a single, malicious individual or group. A solitary, intentional enemy can be related to (e.g., managed, avoided, or understood) in a more straightforward way than a chaotic world full of diffuse perils. Therefore, seeing an enemy as highly influential in one's life reduces the perceived total hazard in one's environment and thus sustains a sense of personal control. As Becker put it,

we simply cannot allow ourselves to believe in and to live with disinterested, bureaucratic evil. ... Evil must happen because someone cares. And if you can find the somebody, and finger him, then your powers are not without effect in the world. (Becker, 1969, p. 140)

According to this view, perceiving clearly identifiable enemies with far-reaching influence over diverse negative outcomes protects individuals from the threatening realization that their control over circumstantial hazards is severely limited. If this account of enemyship's psychological function is correct, then individuals dispositionally low in perceived personal control should be motivated to ascribe greater influence to an enemy when they are reminded of the many sources of random hazard that exist in their environment. We tested this hypothesis in Study 1 by exposing individuals low (vs. high) in perceived internal locus of control to an external hazard prime and observing whether they subsequently saw a personal enemy (but not any aversive figure) as having more influence over their lives. Study 2 was designed to conceptually replicate this effect using an experimentally manipulated threat to perceived control over chaotic hazards and measuring attributions of influence to an enemy in the political sphere. Specifically, we tested whether threatening people's perceived control over chaotic hazards would lead them to attribute more surreptitious influence to the opponent of their preferred candidate in the 2008 U.S. presidential election (but not to diffuse sources of influence unlinked to a focal enemy).

We also sought to examine the situational conditions under which people are more likely to compensate for a control threat by attributing influence to an enemy. On the basis of substantial anthropological evidence, M. Douglas (1966) argued that perceptions of the broader social system affect how people assign power to other entities as a means of coping with personal control concerns. When the social system is perceived as ordered-that is, when the local institutions of economic regulation and law enforcement appear stable and reliable-people tend to bolster their belief in the strength of the system and the benevolent power of the government. Empirical support for this notion is provided by Kay, Gaucher, Napier, Callan, and Laurin (2008), who showed that people compensate for threats to their perceived personal control by ascribing increased power to the government. Specifically, participants who either dispositionally perceived the government to be benevolent and ordered or who lived under governments ranked on an international scale as relatively noncorrupt were more likely to bolster the system as a means of control compensation than those who perceived themselves to be living under disordered (i.e., corrupt and unreliable) governments.

In contradistinction to this tendency, M. Douglas (1966) contended that when the system appears disordered-when economic and law enforcement institutions appear ineffectual and unable to provide protection from external threats-people tend to attribute negative influence to an enemy, rather than positive influence to the government, as a means of compensating for personal control concerns. We believe this analysis has interesting implications for cross-cultural differences in constructions of enemyship (Adams, 2005). It is possible that differences in the normativity of enemy- 
ship between West Africa and North America are due, at least in part, to differences in the perceived order of the local government (see Brown, 2000; Hutchful \& Aning, 2006). ${ }^{1}$

We empirically assessed this possibility on a smaller scale by manipulating perceptions of system order among a sample of U.S. citizens. Specifically, on the basis of M. Douglas's (1966) analysis and Kay et al.'s (2008) findings, we hypothesized that participants led to perceive their social system as ordered would compensate for a personal control threat by bolstering the perceived strength and resiliency of the system; in contrast, those led to perceive the social system as disordered would react to a personal control threat by attributing exaggerated influence to a personal enemy. We tested these hypotheses in Study 3 by exposing participants to a control threat (vs. no threat) and subsequently priming them to view the United States as either an ordered or a disordered system. We then assessed their spontaneous attributions of causal influence over negative life events to a hypothetical enemy, as well as their belief in the strength and order of the U.S. social system and government.

Finally, we were interested in demonstrating the positive psychological effects Becker (1969) associated with enemyship. If perceiving powerful enemies indeed serves to focalize diffuse external hazards, then individuals who are exposed to an enemy figure conducive to this process should show reduced perceptions of chaotic risk and, consequently, increased feelings of personal control. In light of the aforementioned enemyship research (e.g., Adams, 2005) and M. Douglas's (1966) theorizing, we propose that enemies perceived as possessing ambiguous power are especially conducive to the focalization process. This is because ambiguously powerful enemies are capable of conceivably perpetrating more diffuse negative acts. In contrast, if the enemy's powers are explicitly known or if the enemy is weak, then people will have difficulty perceiving that enemy as responsible for many of the chaotic harms one may encounter in the environment. This analysis suggests, somewhat counterintuitively, that exposure to an ambiguously powerful enemy, but not to an explicitly powerful or weak enemy, will lead people whose control has been threatened to report decreased perceptions of external risk and greater feelings of personal control. To test this hypothesis, in Study 4 we manipulated control threat, exposed participants to either an ambiguously powerful, explicitly powerful, or weak enemy figure, and then measured their perceptions of future pessimistic risk and internal locus of control.

\section{Study 1}

Becker (1969) claimed that people will be motivated to compensate for concerns with low personal control over chaotic hazards by attributing influence to an enemy. To empirically test this hypothesis, we reminded participants who were high and low in internal locus of control of either external, generally unpredictable hazards or of self-inflicted hazards that are largely within one's own power to prevent. We then asked participants to describe a relationship with either a personal enemy or, in an aversive target comparison condition, a person who is highly annoying but not malicious. We predicted that reminders of external hazards would lead participants low, but not high, in internal locus of control to attribute more influence to a personal enemy but not to a generically aversive other.

\section{Method}

Participants were 104 (63 women) undergraduates at the University of Kansas (Lawrence, KS) who received course credit for taking part in a purported study on personality and media attitudes. They were randomly assigned to conditions in a 2 (threat: external hazards vs. self-inflicted hazards) $\times 2$ (target: enemy vs. annoyer) factorial design with internal locus of control serving as an individual-difference moderator. The dependent variable of interest was the degree of influence attributed to the target.

Locus of control. Weeks prior to the experimental sessions, participants completed Duttweiler's (1984) 28-item Internal Control Index (ICI), which has been shown in prior research to have good comparative validity and reliability (Furnham \& Steele, 1993). Sample items include "Whenever something good happens to me I feel it is because I've earned it" and "When part of a group I _ prefer to let other people make all the decisions" (reverse-scored). Responses were made on a 5-point scale ranging from rarely (less than 10\% of the time) to usually (more than $90 \%$ of the time). Responses showed good internal reliability $(\alpha=.74)$ and were averaged to form composite ICI scores. Actual scores ranged on a 5-point scale from 2.70 to 4.52 $\left(M_{\text {grand }}=3.65\right)$, with higher scores indicating greater perceived internal locus of control.

Threat manipulation. In private cubicles, participants completed all materials on a computer program designed with MediaLab software (Jarvis, 2004). The threat manipulation followed a neutral measure of media preferences included to bolster the cover story. All participants were instructed to study statistics that they would answer questions about later in the study. The statistics reported the annual number of deaths in the United States due to particular causes. Participants in the external hazard condition viewed statistics reporting deaths due to largely chaotic and unpredictable causes (e.g., food poisoning, natural disasters, or homicide). Participants in the self-inflicted hazard condition viewed statistics reporting deaths due to self-inflicted causes that were relatively more predictable and within one's control (e.g., risky sexual behavior, alcoholism). All participants were exposed to 10 different examples of cause of death, eight causes from the main category (external or self-inflicted) and two from the other category to minimize demand and suspicion. The total number of annual deaths reported for each category was fabricated to be consistent across conditions, so that the conditions differed only in the salience of external versus self-inflicted hazards and not in the overall salience of death.

Target manipulation and influence measure. Then, in an ostensibly unrelated task on personal relationships, participants

\footnotetext{
${ }^{1}$ The possibility that Ghana might well be perceived as a disordered system by many of its citizens is supported by Hutchful and Aning's (2006) observation that, for a long period in the middle of the 20th century, the country was characterized by "misgovernance, decay, and economic implosion" (p. 216). Although more recent decades have seen relatively benevolent economic trends and reduction in governmental corruption in Ghana, this historical shift has been largely facilitated by the rise to power of regimes that gained political clout through identification of clear public enemy figures (Brown, 2000) and by the resilience of Ghanaian social networks, which include clear enemyships (Adams, 2005; Hutchful \& Aning, 2006).
} 
were asked to draw on experience to describe a significant interpersonal relationship in their lives. Those in the enemy condition were instructed to think about having a hostile relationship with a person whom they disliked and would consider a personal enemy. Participants in the annoyer condition were asked to call to mind a frustrating relationship with someone who was always "getting on your nerves." Participants in both conditions typed a few short paragraphs describing their relationship to this person.

Next, participants answered a single-item measure of target influence: "To what extent does this person influence what happens in your life?" $(0=$ not at all, $7=$ very much $)$. They also answered a manipulation check question assessing whether the personal enemy was perceived as more hostile than the personal annoyer: "How hostile are this person's intentions towards you?" $(0=$ not very hostile, $7=$ very hostile $)$.

\section{Results and Discussion}

Inspection of the written target descriptions revealed that participants were able to call to mind both a malicious personal enemy (sample description: "She lies, cheats, deceives those she supposedly cares about, and is overall a bad person") and an annoying other (e.g., "She never stops talking and what she has to say is neither interesting nor a point of view I agree with. She is impolite and I cannot get away from her").

In this and the following studies, we originally performed our primary analyses including gender as a between-subjects variable. Because we observed no significant main effects or interactions involving gender, we omit gender from our reporting of the results to simplify presentation.

Manipulation check. To test the effectiveness of our target manipulation and to examine possible interactive effects of our predictor variables on perceptions of the target's global hostility (we expected none), we regressed target hostility ratings onto threat (external hazards vs. self-inflicted hazards; dummy coded), target (enemy vs. annoyer; dummy coded), ICI score (continuous and centered), and their interactions. The three-way interaction was nonsignificant, $t(96)=0.47, p=.64$. However, the predicted main effect for target emerged, $\beta=.37, S E=.31, t(100)=4.06$, $p<.001$, such that participants saw an enemy figure as more hostile than an annoyer.
Target influence. To test our primary hypothesis, we submitted target influence ratings to the same Target $\times$ Threat $\times$ ICI regression analysis. All lower order effects were qualified by the predicted three-way interaction, $\beta=-.38, S E=1.89, t(96)=$ -2.04, $p=.04, R_{\text {adj }}^{2}=.13$. Following West, Aiken, and Krull (1996), and to test our prediction that a significant Threat $\times$ ICI interaction would emerge only in the enemy target condition, we recoded threat using contrast coding $(-1,1)$ and ran separate models in which target was alternately dummy-coded as enemy $=$ 0 , annoyer $=1$ and enemy $=1$, annoyer $=0$. As predicted, the Threat $\times$ ICI interaction was significant in the enemy condition (enemy $=0$ ), $\beta=.61, S E=.77, t(96)=3.29, p<.01$, but did not reach significance in the annoyer condition (annoyer $=0$ ), $\beta=$ $.14, S E=.56, t(96)=1.06, p=.29$. We plotted the three-way interaction in Figure 1 at one standard deviation above and below the centered ICI mean (Aiken \& West, 1991).

Consistent with predictions, simple slopes analyses revealed that when participants were exposed to external hazards, ICI was negatively and significantly associated with enemy influence ratings, $\beta=-.46, S E=.64, t(97)=-2.97, p<.01$. Also supporting predictions, comparison of the predicted means at one standard deviation below the centered ICI mean showed that low-ICI participants attributed more influence to an enemy if they were exposed to external hazards compared to self-inflicted hazards, $\beta=.72, S E=.75, t(96)=3.07, p<.01$. Comparison of the predicted means at one standard deviation above the ICI mean revealed, unexpectedly, that high-ICI participants attributed more influence to an enemy after reminders of self-inflicted hazards, $\beta=-.42, S E=.64, t(96)=-2.06, p=.04$.

In contrast to the enemy influence scores, simple slopes analyses within the annoyer condition revealed no significant effects ( $\beta \mathrm{s}<$ $.11, p \mathrm{~s} \geq .12$ ).

The results of Study 1 confirm our hypothesis that individuals with low levels of perceived personal control would respond to reminders of external hazards by attributing more influence to a personal enemy. Specifically, low-ICI individuals reminded of lethal risks resulting from forces beyond their personal control perceived a personal enemy as having more influence over their lives, but did not change their perceptions of a highly annoying other. These findings support our theoretical claim that individuals

\section{Enemy Target}

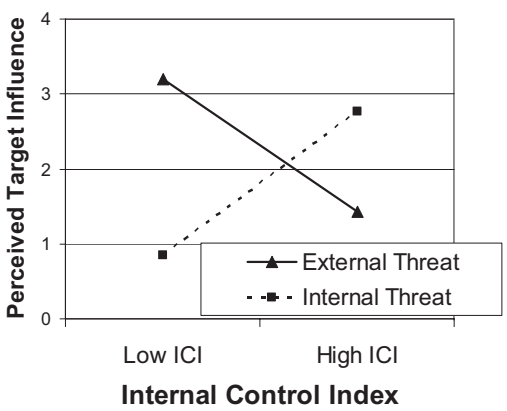

Annoyer Target

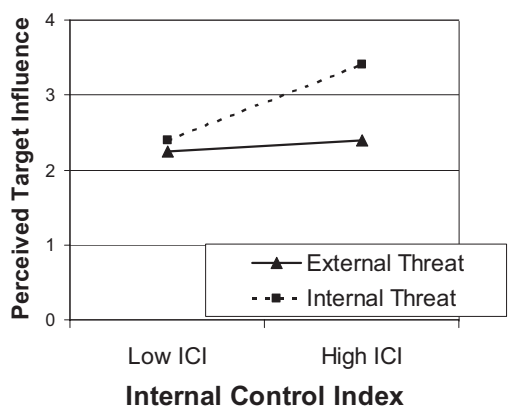

Figure 1. Target influence ratings as a function of target, threat condition, and Internal Control Index (ICI) score (Study 1). Higher scores indicate greater ascribed target influence. Scale ranges from 0-7. 
are motivated to perceive enemies as influential in response to concerns about low personal control over chaotic hazards, even when the salient chaotic hazards are outside of the enemy's likely powers.

We did not predict that high-ICI participants would ascribe more influence to an enemy when self-inflicted hazards were salient. One plausible interpretation of this effect is that people who consider themselves in control of their lives react to reminders of their own potential to negatively influence their lives by ascribing more influence to an enemy figure. Further research is required, however, before making strong conclusions regarding this effect.

Having obtained initial evidence that people compensate for concerns with personal control by attributing greater influence to an enemy, we attempted to replicate this effect in Study 2 with a more direct manipulation of perceived control over external, chaotic hazards. Additionally, we examined whether the process we observed in the domain of personal enemyship would extend to perceived enemies in the political sphere.

\section{Study 2}

Whitson and Galinsky (2008) recently showed that people respond to threats to their personal control by endorsing perceptions of (often illusory) patterns in their environment, including conspiracy theories. These results accord with our current conceptualization, which suggests that conspiracy theories enable individuals to focalize diffuse threats to their perceived control by linking together apparently random negative events in a direct causal chain tracing back to a clearly identifiable enemy. In Study 2, we assessed this analysis and extended Whitson and Galinsky's findings to a more ecologically valid context by testing whether, on the eve of the 2008 U.S. presidential election, participants would respond to a personal control threat by strengthening their belief in the conspiratorial influence of a political enemy figurespecifically, the opponent of their preferred presidential candidate (either Senator John McCain or former Senator Barack Obama). Support for this hypothesis would suggest that personal control concerns played a key role in the creation and media dissemination of elaborate conspiracy theories just prior to the 2008 election (Towery, 2008).

To test this hypothesis, we manipulated control threat by reminding participants of either chaotic hazards beyond their control or relatively more controllable aspects of their lives. We then measured perceptions of enemy influence by asking participants to rate their level of belief in election-related conspiracy theories implicating the opponent of their preferred candidate (e.g., that the opponent candidate was intending to bias the election by manipulating voting machines). We predicted that participants under control threat (vs. no threat) would be more likely to view their political enemy as having far-reaching conspiratorial powers, even when those powers had no direct bearing on the chaotic hazards made salient by the control threat manipulation.

Also, to further establish the unique ability of enemy figures to serve as focal points for concerns with uncontrollable threats, we wanted to show that our manipulation specifically increased motivation to ascribe influence to a clearly identifiable enemy figure. We therefore predicted that a control threat would increase endorsement of enemy-led conspiracies but not of election-related conspiracies that were unconnected to the clear enemy figure of the opponent candidate. In addition, because we hypothesize that it is the enemy's perceived influence that helps minimize personal control concerns, we predicted that our manipulation would not influence ratings of the political enemy's interpersonal warmth, which prior research has shown is independent of perceptions of power (Fiske, Cuddy, Glick, \& Xu, 2002). Support for these hypotheses would increase our confidence that heightening control concerns uniquely affects perceptions of an identifiable enemy's power and does not simply engender general suspiciousness, apprehension over unwanted outcomes, or generically negative attitudes toward an enemy figure.

\section{Method}

Participants were 59 undergraduates ( 32 women) who received candy for their participation. All data were collected on the University of Kansas (Lawrence, KS) campus on November 3, 2008, the day prior to the U.S. presidential election. Participants were given a packet containing all experimental materials.

Control threat manipulation and check. The control threat manipulation followed a neutral personality filler meant to distract participants from the centrality of the manipulation. The manipulation consisted of a questionnaire on which participants indicated their agreement with nine statements regarding their personal control over various outcomes. All participants responded to four filler statements designed not to threaten perceived personal control (e.g., "I have control over the kinds of clothing I wear"). In the control threat condition, the five remaining items were designed to threaten participants' perceptions of control over chaotic risks: "I have control over ... whether I am exposed to a disease; natural disasters and their possible effects on me; whether my family members suffer or not; how my investments or job prospects fare in the economy; whether I encounter risks while traveling." In the no-threat condition, the five remaining items were designed not to threaten perceptions of personal control: "I have control over . . how much TV I watch; my own perceptions of other people; when I study and do homework; who I choose to date; the types of music I listen to."

All responses were made on 5-point scales $(1=$ strongly disagree, 5 = strongly agree). Although the particular set of items participants completed was intended as our manipulation of control threat, responses to the items showed the expected main effects, such that control ratings for the items designed to threaten control were significantly lower than for the filler items within the control threat condition and for the corresponding, nonthreatening items in the no-threat condition (both $p \mathrm{~s}<.001$ )

After completing the manipulation, participants answered a question designed to test its effectiveness: "In general, how much control do you feel you have over what happens in your life?" $(1=$ none at all, 6 = very much).

Dependent measures. After the control threat manipulation, participants filled out an "Election Attitudes Survey" containing nine items (answered along a scale of $1=$ disagree, $6=$ agree) that constituted our dependent measures. Specifically, participants were asked three items each about the extent to which they endorsed (a) election-related conspiracy theories directly implicating the opponent of their chosen candidate ("The opponent has been coordinating efforts to keep members of your party from 
voting in this year's election," "Mail fraud perpetrated by the opponent's campaign is likely to bias the outcome of mail-in ballot in this year's presidential election," and "The opponent is working with powerful money interests to win the election through manipulation of voting machines across the country"; $\alpha=.60$ ), (b) perceptions of the opponent candidate's interpersonal warmth ("The opponent cares about other people," "The opponent empathizes with others," and "The opponent wants to help improve people's lives"; $\alpha=.83$ ), and (c) election-related conspiracies not implicating the opponent candidate ("Extremist groups are plotting to sway this year's presidential election in favor of the opponent," "Members within the highest levels of government and business are acting to bias the election in favor of the opponent," and "Special interest groups who are using the opponent to push their own agendas are attempting to unfairly influence the presidential election"; $\alpha=.55$ ). The nine items were presented in a fixed random order. Responses on each set of three items were averaged to create three composite scores for belief in opponent-led conspiracies, perceived opponent warmth, and belief in non-opponentled conspiracies, with belief in opponent-led conspiracies serving as our primary measure of attributions of negative influence to a political enemy.

Finally, participants completed a single-item political orientation measure $(1=$ very liberal, $5=$ moderate, $9=$ very conservative $)$ and indicated their preferred candidate in the election. We included these measures to assess the possible moderating influence of political orientation or candidate preference (we expected none).

\section{Results and Discussion}

Manipulation check. As predicted, participants in the control threat condition perceived themselves as having less overall control over their lives $(M=3.40, S D=.48)$ compared to participants in the no-threat condition $(M=4.47, S D=.43), t(57)=9.12, p<$ .001 , suggesting that our control threat manipulation was effective.

Dependent measures. To test whether the control threat manipulation differentially affected our three dependent measures, we performed a 2 (control threat vs. no threat) $\times 3$ (measure: belief in opponent-led conspiracies vs. perceived opponent warmth vs. belief in non-opponent-led conspiracies) multivariate analysis of variance (ANOVA) with measure serving as a within-subjects factor. ${ }^{2}$ After observing the predicted interaction, $(F(2,54)=5.37$, $p<.01, \eta^{2}=.17$, we conducted separate control threat versus no-threat ANOVAs on each dependent measure (relevant means are depicted in Figure 2). Consistent with predictions, participants in the control threat condition reported a stronger belief in opponent-led conspiracies compared to participants in the nothreat condition, $F(1,55)=4.23, p=.04, \eta^{2}=.07$. In contrast, the control threat manipulation had no effect on belief in nonopponent-led conspiracies or perceptions of opponent warmth $(F \mathrm{~s}<1.00, p \mathrm{~s}>.35)$.

The results of Study 2 confirmed our hypothesis that, compared to nonthreatened participants, participants reminded of their lack of control over chaotic hazards would attribute more power to a public enemy figure, whereas control threat would not influence perceptions of conspiratorial power unconnected to a clear enemy, nor would it influence overall attitudes toward the enemy figure. These findings support our claim that people attribute greater influence to a focal enemy figure as a means of compensating for decreased perceptions of personal control. They also rule out the alternative possibilities that the control threat manipulation simply heightened generalized suspicion or generically negative evaluations of an enemy.

In the next study, we further sought to establish the unique link between personal control concerns and enemyship using a more direct measure of an enemy's perceived influence over one's life, while further controlling for the possibility (also addressed in Study 1) that heightened control concerns lead people to attribute increased influence to any interpersonally significant other (and not just an enemy). A second goal of Study 3 was to examine the potential moderating influence of perceptions of the broader social system.

\section{Study 3}

Study 3 provided a further test of the effect of a personal control threat on perceptions of an enemy's influence, but built on the prior two studies in a number of important ways. First, whereas Study 1 used a single item to measure perceptions of a personal enemy's general influence, in Study 3, we used a more explicit measure of people's preference for viewing a personal enemy as directly responsible for hypothetical negative events in their everyday lives. This measure also allowed us to investigate whether, in line with our conceptualization, people would be less willing to attribute negative events to random forces after a control threat. We also measured whether people view a personal friend as directly responsible for positive events. This allowed us to test our hypothesis that people attribute exaggerated influence to a personal enemy, but not to a personally significant but benevolent other, as a means of compensating for decreased perceptions of personal control. Finally, we included a measure of self-reported affect to test the alternative possibility that our hypothesized findings were simply due to affective consequences of our independent variables.

Furthermore, Study 3 examined the potential moderating influence of perceptions of the broader social system. As described earlier, based on empirical (Adams, 2005) and anthropological (M. Douglas, 1966) evidence that enemyship is more common when local social systems are economically and politically unstable, we hypothesized that people concerned with personal control are especially likely to attribute influence to enemies when they perceive the social system as disordered - that is, when local institutions of law and order cannot be depended on for protection from harm-compared to when the system is perceived to be intact and resilient. We tested this hypothesis by priming participants to think of the United States as either an ordered system or a disordered system. We predicted that participants primed to think of the United States as a disordered system would respond to a personal control threat by attributing more negative (but not neutral or positive) events to an imagined personal enemy and fewer negative

\footnotetext{
${ }^{2}$ For all analyses in Study 2, we included political orientation $\left(M_{\text {Grand }}=\right.$ $3.75, S D=1.95)$ and candidate intended to vote for (Obama $=76 \%$ of the sample, McCain $=20 \%$ ) as potential individual-difference moderators. In none of these analyses did we observe significant main effects or interactions involving political orientation $(F \mathrm{~s}<2.00, p \mathrm{~s}>.30)$ or preferred candidate $\left(F_{\mathrm{s}}<1.00, \mathrm{ps}>.40\right)$, so we omit these results from our discussion. It should be noted, however, that given the predominantly liberal nature of our sample and the relatively high percentage of Obama voters, these null results cannot be interpreted as conclusive due to a restricted range.
} 


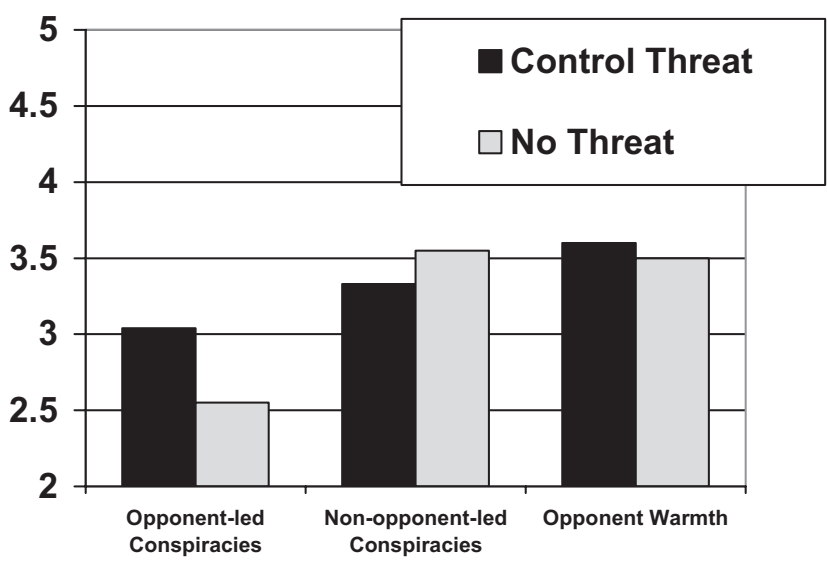

Figure 2. Endorsement of opponent-led conspiracies, non-opponent-led conspiracies, and opponent warmth as a function of control threat (Study 2). Higher scores indicate greater belief in conspiracies or higher perceived warmth. Scale ranges from 1-7.

events to random chance, but that this effect would be eliminated when the United States was portrayed as an ordered system. Building on the work of Kay et al. (2008), we predicted that participants in the ordered system condition, rather than attributing more negative influence to a personal enemy, would compensate for a personal control threat by boosting the perceived strength and order of the system. For participants in the disordered system condition, we predicted no such threat-induced boost in ratings of system strength.

\section{Method}

Participants were 91 (52 women) undergraduates at the University of Kansas (Lawrence, KS) who received course credit for taking part in a study of personality and political attitudes. Six participants were excluded from our analyses because they were not native speakers of English and professed difficulty understanding our measures, and 3 participants were excluded because they were suspicious about the true nature of our study. The remaining 82 participants (48 women) were randomly assigned to conditions in a 2 (control threat vs. no threat) $\times 2$ (ordered system vs. disordered system) factorial design, with event attributions (to a personal enemy, friend, or randomness) serving as the dependent variable of interest. Because the materials used to manipulate perceptions of system order made reference to current events, we collected all data in January and February of 2009, as President Obama was coming into office and his administration's economic stimulus package was moving through the U.S. legislature and as concerns about the economic recession of that time were relatively high.

Control threat manipulation and check. Participants first completed a packet of ostensible personality and opinions measures. After completing a neutral filler questionnaire (similar to that used in Studies 1 and 2), participants were randomly assigned to complete either the control threat or the no-threat induction described in Study 2. They then answered the same manipulation check item used in Study 2.

System type manipulation. In an ostensibly unrelated task, participants were asked to read an essay allegedly selected at random from a larger collection of essays taken from leading political magazines. In accordance with the cover story, participants were asked to read the essay carefully to answer questions about its content later. Participants were randomly assigned to read one of two essays. In the ordered system condition, the essay stated that the U.S. government is well equipped to overcome the current economic crisis. Furthermore, the essay claimed that crime rates are declining as a direct result of improved law enforcement and included general assertions that the United States represents an ordered system (e.g., "Our system has met the recent economic and political challenges head on, and appears to be steering us back on the prosperous track").

In the disordered system condition, the essay stated that the U.S. government is completely unequipped to handle the current crisis, that the crisis is largely the result of the system's lack of order, and that U.S. crime rates are increasing as a result of incompetence on the part of U.S. law enforcement agencies. This essay, partially modeled after system threat manipulations used in the system justification literature (e.g., Lau, Kay, \& Spencer, 2008), ${ }^{3}$ included statements like "The governmental and economic infrastructure of this country has proven to be simply inadequate when it comes to protecting citizens. The system has failed us." The essays were fabricated by the experimenters and were matched in length, overall tone, and the particular issues discussed. Multiple efforts were taken to enhance the essays' apparent legitimacy.

Event attributions measure. Next, participants completed the measure of attributions to an enemy, friend, or randomness on computers. The first screen instructed participants to imagine a hypothetical personal enemy and a hypothetical personal friend entering their lives in the course of the coming year. Participants were told they could draw on their imagination and past relationship experience to visualize these individuals. Instructions detailed that the imagined enemy should be someone "whose values go against all your own values, who always seems out to get you, and who hurts you in every way possible," while the imagined friend should be someone "who always seems to have your best interests at heart, and who helps you in every way possible."

With their hypothetical enemy and friend in mind, participants were presented with a list of hypothetical events and instructed, "For each possible event that could happen in the course of the next year, click on what you would consider to be the MOST LIKELY cause of that event." For each event (presented independently on separate screens), participants could select one of four options: "Your new friend caused this event," "Your new enemy

\footnotetext{
${ }^{3}$ From the perspective of system justification theory, one might have expected participants to compensatorily boost the perceived order of the system after a threat to the system's integrity in the form of our disordered system manipulation. However, compared to system threat manipulations commonly used in other studies (e.g., Lau et al., 2008), our disordered system essay was extensive and, in light of concerns about the U.S economy at the time of data collection, probably fairly convincing to participants. Accordingly, we report a main effect of system type such that participants in the disordered (vs. ordered) system condition perceived the system as overall less ordered. Furthermore, studies such as those conducted by Lau et al. (2008) often measure the effects of system threat on a domain indirectly related to the actual economic and institutional integrity of the system, such as traditionalist attitudes. For these reasons, we believe that our conceptualization and findings are broadly consistent with prior work on compensatory system beliefs and system justification.
} 
caused this event," "This event happened randomly (neither your friend nor your enemy caused it)," or "This event is not likely to happen." There were 24 events in total, 8 of them negative in valence, 8 positive, and 8 not clearly negative or positive (see the Appendix). Participants were randomly assigned to view the events in one of two fixed random orders (preliminary analyses revealed no significant effects involving order, so it is omitted from subsequent analyses).

Perceptions of system strength. Participants were then asked to think back to the system-relevant essay they had read and to answer three items that constituted our measure of perceived system order and strength in the face of crisis: "How severe is the current economic crisis facing the U.S.?" $(0=$ not severe at all, 7 = very severe), "What are living conditions currently like for citizens of the U.S.?" $(0=$ not secure at all, $7=$ very secure $)$, and "How capable is the U.S. government of effectively dealing with the current economic crisis?" $(0=$ not capable at all, $7=$ very capable). Participants were asked to make responses based on their understanding of the essay. Responses to the first question were reverse-scored. Responses to the three items showed good reliability $(\alpha=.73)$ and so were averaged to create composite scores of belief in system strength, with higher scores indicating greater perceived strength.

Affect measure. To control for the possibility that our hypothesized effects were simply due to changes in mood or affect caused by our independent variables, we included a 20 -item version of the Positive and Negative Affect Schedule (Watson, Clark, $\&$ Tellegen, 1988) self-report affect measure. We averaged scores to form composite positive ( $\alpha=.82$; e.g., enthusiastic) and negative ( $\alpha=.82$; e.g., nervous) affect scores.

\section{Results and Discussion}

Control threat manipulation check. As expected and replicating Study 2, participants in the control threat condition reported less overall personal control $(M=3.43, S D=.83)$ than participants in the no-threat condition $(M=4.15, S D=.83)$, $t(80)=3.93, p<.001$.

Event attribution measure. To measure the number of enemy attributions made for negative, positive, and neutral hypothetical events, we recoded all responses such that a target response of "Your new enemy caused this event" was scored as 1 and all other possible responses were scored as 0 . We then summed responses within each type of event to create separate enemy attribution scores for negative, positive, and neutral events. We performed parallel versions of this procedure for attributions to randomness, attributions to a friend, and attributions of not likely to happen. Table 1 displays the average number and percentage of each type of attribution for each type of event (negative, positive, or neutral) according to condition.

We performed our primary analyses with tests designed for low-frequency-count data, namely Poisson and negative binomial regression (Coxe, West, \& Aiken, 2009).

Enemy attributions for negative events. We first tested our prediction that, when the broader system was portrayed as disordered, control-threatened participants would attribute more negative events to a personal enemy. Because these data were overdispersed $(\varphi=1.35)$, we regressed enemy attributions for negative events onto threat (control threat vs. no threat), system type (or-

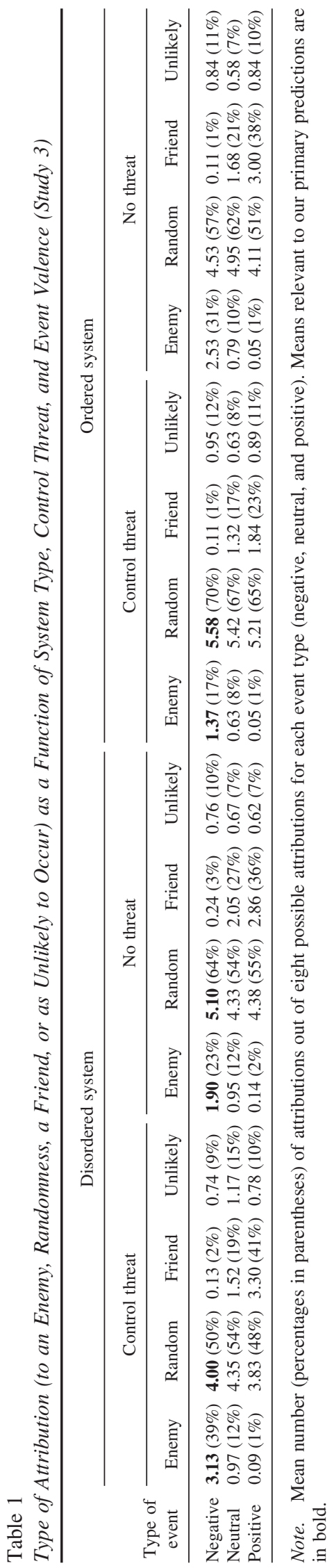


dered vs. disordered), and their interaction using a negative binomial distribution. The predicted interaction emerged, $\beta=1.11$, $S E=.35, \chi^{2}(1, N=78)=10.05, p<.01$. Pairwise comparisons revealed that, within the disordered system condition, controlthreatened participants attributed more negative events to an enemy compared to nonthreatened participants, $\beta=-.25, S E=.13$, $\chi^{2}(1, N=78)=3.89, p=.05$.

Also supporting our primary prediction, within the control threat condition, disordered system participants attributed more negative events to an enemy compared to ordered system participants, $\beta=$ $-.41, S E=.14, \chi^{2}(1, N=78)=8.43, p<.01$, whereas system type had no effect within the no-threat condition, $\beta=-.14, S E=$ $.14, \chi^{2}(1, N=78)=1.02, p=.30$.

Somewhat unexpectedly, within the ordered system condition, control-threatened participants attributed significantly fewer negative events to an enemy compared to nonthreatened participants, $\beta=-.31, S E=.15, \chi^{2}(1, N=78)=4.12, p=.04$. This finding tentatively suggests that, under conditions of system order, a control threat might lead individuals to defensively deny negative enemy influence.

Random attributions for negative events. Next, we tested our prediction that, when the broader system was portrayed as disordered, control-threatened participants would attribute fewer negative events to random forces. Because these data did not show overdispersion $(\varphi=0.90)$, we submitted them to the same Threat $\times$ System Type omnibus test and pairwise comparisons, but using a Poisson distribution. We observed the predicted interaction, $\beta=-.45, S E=.20, \chi^{2}(1, N=78)=4.93, p=.03$. Pairwise comparisons revealed that, within the disordered system condition, control-threatened participants attributed fewer negative events to randomness compared to nonthreatened participants, although this effect was marginally significant, $\beta=.12, S E=.07, \chi^{2}(1, N=$ $78)=2.90, p=.08$. Also as predicted, within the control threat condition, disordered system participants attributed significantly fewer negative events to randomness compared to ordered system participants, $\beta=.17, S E=.06, \chi^{2}(1, N=78)=7.82, p<.01$. The comparisons for threat within the ordered system and system type within the no-threat condition did not reach significance $\left(\chi^{2} \mathrm{~s}<2.00, p \mathrm{~s}>.15\right)$.

Friend attributions for positive events. To test whether participants were responding to a control threat in a disordered system by making more attributions to any interpersonally significant other rather than specifically to a personal enemy, as we claim, we performed a parallel analysis (using a Poisson distribution; $\varphi=$ 1.06) on the number of attributions for positive events made to a hypothetical friend. This analysis revealed a significant interaction, $\beta=.63, S E=.28, \chi^{2}(1, N=78)=5.28, p=.02$. As expected, however, pairwise comparisons revealed no significant effect of threat on friend attributions within the disordered system condition $(p=.40)$, nor of system type within the no-threat condition $(p=.80)$. Rather, this interaction was due to controlthreatened participants in the ordered system condition attributing fewer positive events to a friend compared to nonthreatened participants in the ordered system condition, $\beta=-.24, S E=.11$, $\chi^{2}(1, N=78)=5.16, p=.02$, and control-threatened participants in the disordered system condition, $\beta=-.29, S E=.10, \chi^{2}(1, N=$ $78)=8.18, p=.01$. Although we did not predict this effect, it is possible that, within an ordered system, threats to control increase a desire to see oneself-rather than an interpersonally significant other-as responsible for positive life occurrences. More importantly, however, the null effect for threat in the disordered system condition is consistent with our claim that people respond to control threats in a disordered system by ascribing an enemy control over negative events but not by ascribing a friend influence over positive events.

Perceptions of system strength. To test whether participants in the ordered system condition compensated for a control threat by boosting the perceived strength of the U.S. economic-political system, we submitted composite system strength scores to a 2 (control threat vs. no threat) $\times 2$ (disordered vs. ordered system) ANOVA. As expected, we observed a main effect for system type, $F(1,74)=106.37, p<.001, \eta^{2}=.61$, such that participants who read the disordered system essay indeed saw the system as less ordered $(M=2.41, S D=.92)$ compared to participants who read the ordered system essay $(M=4.49, S D=.89)$. The predicted interaction between control threat and system type also emerged $F(1,74)=3.90, p=.05, \eta^{2}=.05$ (see Figure 3 for means). Consistent with predictions, pairwise comparisons (least significant difference) revealed that within the ordered system condition, participants who received a control threat ascribed more overall strength to the U.S. system compared to nonthreatened participants, $F(1,74)=10.77, p<.01$.

Affect. Submitting composite positive and negative affect scores to Control Threat $\times$ System Type ANOVAs revealed no significant main effects or interactions $(F \mathrm{~s}<1.00, p \mathrm{~s}>.24)$. Furthermore, including affect scores as covariates in our primary analysis did not significantly affect the predicted pattern of results.

The results of Study 3 build on and extend the findings of the previous studies in two ways. First, they provide a conceptual replication of the finding in Study 1 that people minimize concerns with low personal control over chaotic hazards by attributing influence to a personal enemy (but not any interpersonally significant other) using a situational manipulation of perceived control and a more explicit measure of a personal enemy's perceived influence over one's life. Through this measure, we were able to observe participants creatively construing an imagined enemy as

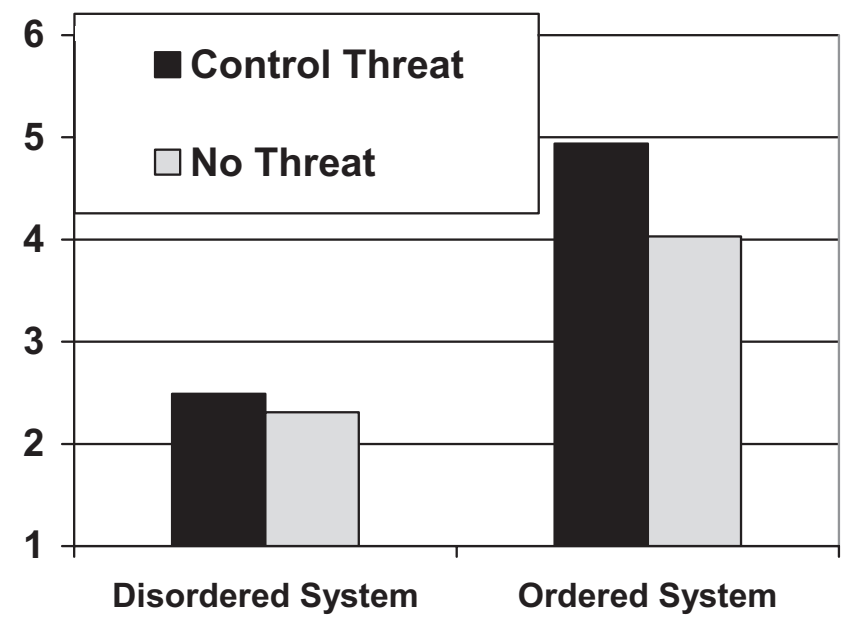

Figure 3. Perceived U.S. system strength as a function of control threat and system type (Study 3). Higher scores indicate greater perceived order and strength of the system. Scale ranges from 0-7. 
being more or less responsible for possible misfortune in their lives. Importantly, this measure also allowed us to test whether, in line with our analysis, threatening personal control would make participants less willing to perceive negative events as determined by random forces. Second, Study 3 shows that perceptions of the broader social system play an important moderating role in the effect of control threat on enemy attributions. Specifically, only when the broader social system was portrayed as disordered did participants respond to a control threat by viewing a personal enemy as responsible for negative occurrences in their everyday life. This finding supports M. Douglas's (1966) claim that perceiving powerful enemies as having influence over one's life is an especially useful means of compensating for concerns with low personal control when the broader social system is viewed as incapable of providing protection from harm. It was also specifically under conditions of system threat that control-threatened participants were especially unlikely to attribute negative personal events to random forces.

Participants led to view the system as ordered did not respond to a control threat by attributing more influence to an enemy or to a friend. Rather, they seemed to defensively downplay the extent to which enemies negatively influence their lives. Furthermore, they bolstered their belief in the strength and resilience of the U.S. economic-political system. This result is conceptually consistent with Kay et al.'s (2008) findings that people compensate for a control threat by strengthening their belief in the government's legitimacy and power. However, we expand upon these findings to show that when the system is perceived as disordered, ascribing power to one's enemies, not the government, is a preferred means of compensating for a control threat. Importantly, the fact that control-threatened participants showed a compensatory affirmation of the system suggests that priming participants to view the system as ordered did not simply eliminate defensive reactions to the control threat; rather, it created a psychological environment in which the preferable means of compensating for control concerns was bolstering perceived system strength.

Taken together, the results of Studies 1-3 provide converging evidence that heightening concerns with personal control leads people to attribute influence to a focal, malicious enemy in both personal and political domains. However, we have not yet addressed the second broad hypothesis derived from Becker's (1969) existential perspective, namely, that contemplating enemyship when control concerns are high will, counterintuitively, decrease perceptions of risk in the world and, in turn, bolster perceptions of personal control. Study 4 assessed this possibility.

\section{Study 4}

Study 4 tested the hypothesis that, after exposure to a control threat, contemplating an enemy conducive to the focalization of diffuse threats will reduce perceptions of external risk, which in turn will bolster the individual's sense of control over the environment. As discussed in the introduction, M. Douglas (1966) claimed that people tend to imbue enemies with ambiguous as opposed to explicit power; in other words, while they think of benevolent leaders and heroes as possessing clearly defined, justified powers to work for the common good, they tend to associate enemies with shadowy, poorly understood sources of power and uncanny abilities to mysteriously perpetrate unexpected misdeeds.
Our current conceptualization helps to explain why enemies are typically attributed ambiguous powers. An ambiguously powerful enemy-one whose powers are only vaguely known and who might strike at any moment—can be viewed as responsible for many of the diverse hazards imminent in one's environment. Note that we are not arguing that the enemy has to be directly linked to any and all hazards to serve a control-restorative function; rather, we propose that an ambiguously powerful enemy should serve this function well because his or her influence can potentially account for many and diverse potential threats to one's life and well-being. In contrast, people may have difficulty creatively ascribing influence over multiple, diffuse harms to an explicitly powerful enemy whose capabilities, characteristics, and limitations are already well understood. Similarly, it may be difficult to use a weak enemy as a focal point for concerns with chaos and control-an enemy known to be incompetent is unlikely to be a satisfactory target for attributions of influence.

If this view is correct, then perceiving ambiguously powerful enemies should be a uniquely effective means of reducing perceptions of chaotic risks in one's environment and therefore bolstering perceived personal control, compared to perceiving explicitly powerful or weak enemies. To test these hypotheses, following a control threat manipulation, we randomly assigned participants to read an article on the terrorist group Al Qaeda that portrayed this political enemy as either ambiguously powerful, explicitly powerful, or weak. We then measured perceptions of future risk and internal locus of control. We predicted that a control threat would increase perceptions of risk when Al Qaeda was portrayed as explicitly powerful or weak but that this effect would be eliminated, and perhaps reversed, when Al Qaeda was portrayed as ambiguously powerful. We also predicted that participants in the control threat condition who were exposed to an ambiguously powerful enemy would subsequently show greater internal locus of control relative to participants exposed to an explicitly powerful or weak enemy and that this effect would be mediated by a corresponding reduction in perceived negative risks.

\section{Method}

A total of 91 (73 women) undergraduates at the University of Kansas (Lawrence, KS) completed an online survey for course credit. Initial instructions presented a cover story that the study was examining the relation between personality and memory, and participants were therefore asked to complete the survey in a single sitting in a quiet, distraction-free environment. Participants were randomly assigned to conditions in a 2 (control threat vs. no threat) $\times 3$ (enemy type: ambiguously powerful vs. explicitly powerful vs. weak) factorial design, with ratings of future risk and personal locus of control as the primary dependent measures.

Control threat manipulation. Participants were randomly assigned to receive a computerized version of either the control threat or no-threat induction and manipulation check question used in Studies 2 and 3.

Enemy type manipulation. Next, participants were instructed that they would read an essay randomly chosen from a database of articles from credible online news magazines. They were instructed to read through the article thoroughly because (as per the cover story) they would later answer questions about its content. The experimenter-fabricated articles presented informa- 
tion on the terrorist organization $\mathrm{Al}$ Qaeda, supplemented by a relevant photograph; however, the details of the information and the photograph varied according to condition.

In the ambiguously powerful enemy condition, Al Qaeda was described as a powerful enemy whose strengths, whereabouts, and probable future activities are poorly understood by U.S. intelligence. This article included statements like "Al Qaeda has an almost supernatural ability to evade detection. . . According to one U.S. officer: 'It's challenging to fight an enemy that you don't even understand." The accompanying photograph depicted a shadowy figure whose outline was recognizable as that of a stereotypic Arab terrorist, carrying a rifle and poised on a rocky outcrop.

In the explicitly powerful enemy condition, Al Qaeda was described as a powerful enemy whose strengths, whereabouts, and probable future activities are well known to U.S. intelligence. This article included statements like "Al Qaeda's capacity as a terrorist organization is well-understood.... According to one U.S. officer: 'It's going to be a challenging fight-we have many resources on our side, but this enemy has local support and the skills and weaponry best-suited to this kind of inner-city combat." The accompanying photograph was a clear image of an Al Qaeda leader in a foreign television broadcast, with a rifle in the background.

In the weak enemy condition, Al Qaeda was described as an incompetent enemy that poses no serious threat to the United States or U.S. armed forces. This article included statements like "Information shows that Al Qaeda is severely lacking in skill, support, and technological capacity.... According to one U.S. officer: 'These guys are a joke-give me an enemy worth fighting!"” The accompanying photograph was a rather unflattering image of an Al Qaeda leader making an awkward expression during an interview. The articles were graphically designed to resemble common online news articles.

Pessimistic future risk measure. After reading the enemy type manipulation article, participants completed a measure of perception of future risk used in prior research (Lerner \& Gonzalez, 2005; Väjstfjäll, Peters, \& Slovic, 2008; Weinstein, 1980). Participants were asked to imagine looking back on their lives 10 years from now and to indicate the likelihood $(1=$ extremely unlikely, 7 = extremely likely) that each of 15 possible events would have occurred. Six of the events were positive in nature (e.g., "My income increased significantly within five years after my first job," "I received favorable medical tests"), while the other 9 events were negative (e.g., "I could not find a job for six months," "I was on an airplane that encountered extreme turbulence”). Following Väjstfjäll et al.'s (2008) procedure, we reversescored positive items and averaged them with the remaining items to create composite scores for pessimistic future risk (where higher scores indicate greater likelihood of encountering undesirable events; $\alpha=.60$ ).

Locus of control. The next questionnaire was Duttweiler's (1984) 28-item ICI scale used in Study $1(\alpha=.83)$.

Enemy type manipulation checks. Finally, participants were asked to think back to the news article they had read and to answer four questions designed to test the effectiveness of our enemy type manipulation. Three questions gauged whether participants in the ambiguously and explicitly powerful enemy conditions indeed saw Al Qaeda as more powerful and threatening than participants in the weak enemy condition ("How powerful is Al Qaeda?" [1 = not powerful at all, 7 = very powerful], "How intelligent are $\mathrm{Al}$ Qaeda's members?" $[1=$ not intelligent at all, $7=$ very intelligent], and "How much of a threat does Al Qaeda pose to the United States?" $[1=$ no threat at all, $7=$ an extreme threat $] ; \alpha=$ .96). One additional item measured whether participants in the ambiguously powerful enemy condition in fact perceived $\mathrm{Al}$ Qaeda to be less well understood than participants in the other two conditions ("How well does U.S. intelligence understand the details of Al Qaeda's operation?" $[1=$ not very well, 7 = very well $]$ ).

\section{Results and Discussion}

Manipulation checks. As expected, and replicating the findings in Studies 2 and 3, participants in the control threat condition reported less overall control over their lives $(M=4.23, S D=.85)$ compared to participants in the no-threat condition $(M=4.70$, $S D=.70), t(97)=2.99, p<.01$.

To test the effectiveness of our enemy type manipulations and to investigate any possible effect of threat condition or interactive effect on perceptions of the enemy (we predicted none), we first submitted our composite measure of Al Qaeda's perceived powerfulness to a 2 (control threat vs. no threat) $\times 3$ (enemy type: ambiguously powerful vs. explicitly powerful vs. weak) ANOVA. The two-way interaction and main effect for control threat were nonsignificant ( $p s>.80)$, and only the predicted main effect for enemy type emerged, $F(2,93)=106.13, p<.001$. Pairwise comparisons (least significant difference) revealed that participants in the weak enemy condition viewed Al Qaeda as significantly less powerful $(M=2.05, S D=1.06)$ compared to participants in the ambiguously powerful $(M=5.81, S D=.76)$ and the explicitly powerful enemy $(M=5.98, S D=1.05)$ conditions (both $p s<.001)$, whereas ratings of enemy power in the ambiguously powerful and explicitly powerful enemy conditions were statistically equivalent $(p>40)$. This latter null effect rules out the possibility that our hypothesized effects were simply due to differences in perceptions of the literal extent of Al Qaeda's power between the ambiguously powerful and explicitly powerful conditions.

Additionally, we tested the discriminant effectiveness of our ambiguously powerful enemy manipulation by submitting our single-item measure of understanding of the enemy to the same omnibus test and pairwise comparisons. Again, we found only a main effect for enemy type, $F(2,93)=32.80, p<.001$ (all other $p \mathrm{~s}>.20$ ), and pairwise comparisons revealed that participants in the ambiguously powerful enemy condition saw Al Qaeda as significantly less well understood by U.S. intelligence $(M=2.69$, $S D=1.40)$ compared to participants in the explicitly powerful $(M=5.30, S D=1.59)$ and weak enemy $(M=5.12, S D=1.32)$ conditions (both $p \mathrm{~s}<.001$ ).

Pessimistic future risk. To test our hypothesis that contemplating an ambiguously powerful enemy would attenuate a controlthreat-induced increase in perceived risk, we submitted our composite measure of pessimistic future risk perceptions to the same 2 (control threat) $\times 3$ (enemy type) ANOVA. We obtained the predicted interaction, $F(2,93)=4.60, p=.01, \eta^{2}=.09$ (relevant means are depicted in Figure 4). Pairwise comparisons (least significant difference) revealed that, among participants exposed to an explicitly powerful or a weak enemy, control threat significantly increased perceptions of future risk $\left(F_{\mathrm{S}}>3.90, p \mathrm{~s}<.05\right)$. 
In contrast, participants exposed to an ambiguously powerful enemy showed a trend in the opposite direction, reporting less future risk under control threat, $F(1,93)=2.78, p=.10$.

As important, participants in the control threat-ambiguously powerful enemy condition perceived significantly less pessimistic future risk than participants in the control threat-weak enemy condition, $F(1,93)=4.76, p=.02$, and marginally less pessimistic future risk than participants in the control threat-explicitly powerful enemy condition, $F(1,93)=2.89, p=.07$. These findings suggest that ambiguously powerful enemies are more likely than weak or explicitly powerful enemies to buffer the effect of a threat to personal control on perceptions of harmful risk, which are exacerbated when other kinds of enemies are contemplated.

Locus of control. To test whether contemplating an ambiguously powerful enemy can actually boost perceived personal control, we submitted ICI scores to the same omnibus ANOVA. We observed the predicted Control Threat $\times$ Enemy Type interaction, $F(2,93)=3.09, p=.05, \eta^{2}=.06$ (see Figure 5). Pairwise comparisons showed that participants exposed to a control threat and subsequently exposed to an ambiguously powerful enemy reported higher ICI levels compared to participants in both the control threat-weak enemy condition and the control threatexplicitly powerful enemy condition $(F \mathrm{~s}>4.90, p \mathrm{~s}<.01)$.

Indeed, when an ambiguously powerful enemy was salient, participants who received a control threat reported higher ICI levels compared to those in the no-threat control condition, $F(1$, $93)=5.21, p=.03$, a difference not observed in the other enemy conditions $(F \mathrm{~s}<1.50, \mathrm{ps}>.20)$. This finding supports our hypothesis that contemplating an ambiguously powerful enemy when one is motivated to minimize control concerns can significantly bolster one's perceived control over the environment. ${ }^{4}$

Mediation of locus of control by pessimistic future risk. According to our hypothesis, contemplating an ambiguously powerful enemy after receiving a threat to personal control reduces perceptions of chaotic risks in one's environment, which in turn bolsters feelings of personal control. We tested this mediational

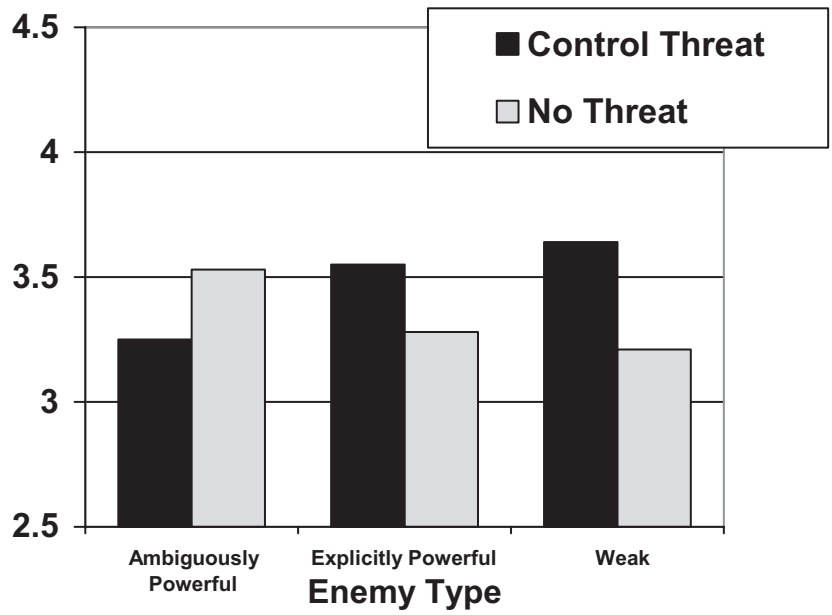

Figure 4. Pessimistic future risk perceptions as a function of control threat and enemy type (Study 4). Higher scores indicate greater perceptions of pessimistic future risk. Scale ranges from 1-7.

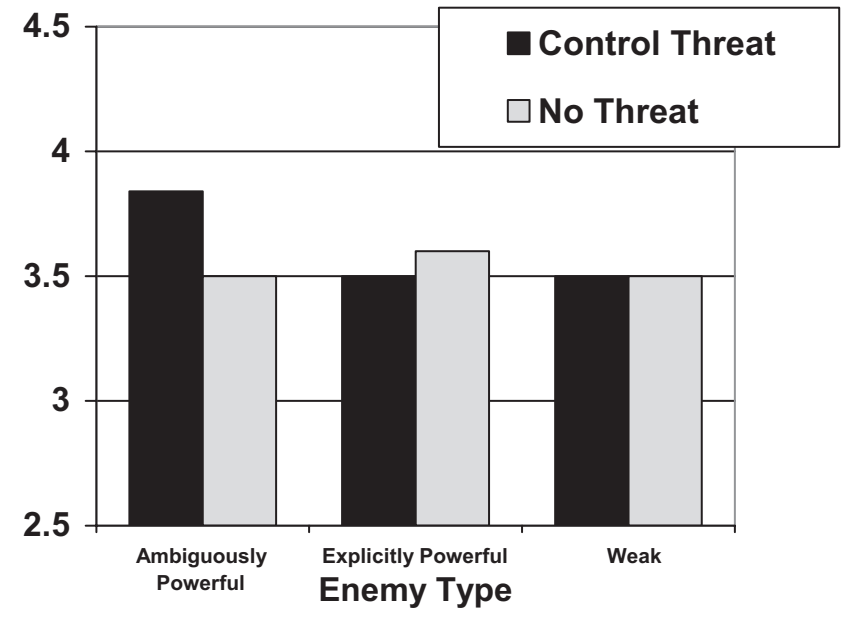

Figure 5. Internal Control Index scores as a function of control threat and enemy type (Study 4). Higher scores indicate greater levels of perceived internal locus of control. Scale ranges from 1-5.

hypothesis using the bootstrapping procedure and corresponding SPSS macro of Preacher and Hayes (2008), regressing ICI scores onto the interaction of enemy type (contrast coded: ambiguously powerful enemy $=1$, explicitly powerful enemy $=-.5$, weak enemy $=-.5$ ) and control threat manipulation (dummy coded: control threat $=0$, no control threat $=1$ ), with pessimistic future risk score entered as the proposed mediator and our main effects (control threat and enemy type) entered as covariates. Five thousand bootstrap resamples were performed. The $95 \%$ confidence interval obtained for the indirect effects of the Control Threat $x$ Enemy Type interaction on ICI scores through the mediator of pessimistic future risk did not contain zero $(-.24,-.04)$. Therefore, we are confident at $\alpha=.05$ that the increase in perceived internal locus of control for control threat-ambiguously powerful enemy participants was mediated by the corresponding decrease in perceptions of future risk (see Figure 6 for a graphical depiction of the mediation model).

To test for the alternative possibility that the effect of the Enemy Type $\times$ Control Threat interaction on risk perceptions was mediated by locus of control, we performed a reverse mediational model in which pessimistic future risk score was entered as the dependent variable and ICI score as the proposed mediator. The obtained confidence interval for this reverse model contained zero $(-.01, .21)$, suggesting that the interactive effect on internal locus of control was mediated by perceived future risk and not vice versa.

The results of Study 4 confirm our hypothesis that a personal control threat would heighten perceptions of negative risks in the

\footnotetext{
${ }^{4}$ Although one might have expected a personal control threat to reduce perceived ICI level in our comparison enemy conditions, the fact that these effects did not emerge is consistent with prior research demonstrating that locus of control is a stable construct fairly resistant to experimental manipulation (see Hans, 2000; Reich \& Zautra, 1990; Underwood, Froming, \& Moore, 1980). This observation, coupled with the large effect size observed for control threat on ICI within the ambiguously powerful enemy condition $(d=$ .80 ), suggests that the process of focalizing threats onto a suitable enemy is a uniquely powerful means of bolstering perceived personal control.
} 


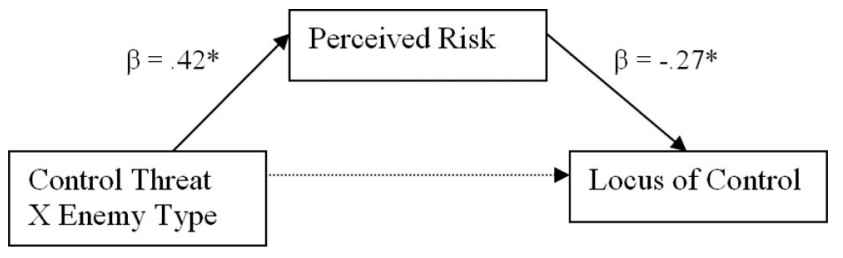

Total Effect: $\beta=-.26^{*}$

Direct Effect: $\beta=-.14$, n.s.

Figure 6. Mediation model. All path coefficients represent standardized regression weights. The direct effect coefficient represents the effect of the interaction on the dependent variable after controlling for the effect of the proposed mediator. Total adjusted $R^{2}$ for the model $=.17, F(4,94)=5.87$, $p<.001 .{ }^{*}$ Significant at $p<.05$.

environment when people contemplate enemies that are not conducive to focalizing risk (i.e., enemies with explicitly known or weak powers) but that this effect would be eliminated and to some extent reversed when people contemplate an ambiguously powerful enemy. Furthermore, this reduction in perceived risk led to a corresponding boost in internal locus of control among participants who had received a control threat and thought about an ambiguously powerful enemy.

\section{General Discussion}

On the basis of Becker's (1969) existential theorizing, we have proposed that perceiving the self as having powerful enemies serves a psychological function for the individual by compensating for threatened perceptions of control over one's environment. Specifically, enemies serve as psychological focal points for what are otherwise diffuse threats to one's life and well-being that are impossible to fully anticipate or control. This analysis suggests that people will imbue enemy figures with exaggerated influence and power when feelings of control are threatened and that perceiving powerful enemies capable of perpetrating diffuse misdeeds will bolster feelings of personal control by reducing perceptions of chaotic risks in one's environment. The current studies provide the first empirical tests of these claims.

Study 1 showed that when people were reminded of the prevalence of chaotic hazard in their environment, those individuals characterized by dispositionally low feelings of personal control were more likely to view a personal enemy as having influence over their lives, but this effect did not extend to perceptions of a generically aversive other. Study 2 provided a conceptual replication of this effect on perceptions of a political enemy in a more ecologically valid context, with an experimental manipulation of perceived control over chaotic hazards. In accord with predictions, situationally reduced feelings of personal control increased participants' belief that a public enemy figure - the opponent of their chosen candidate in the 2008 U.S. presidential election-was wielding power to surreptitiously manipulate the election. This study furthermore showed that the hypothesized effect was not simply due to an increase in generalized suspiciousness, concern with unwanted election outcomes, or generally negative evaluations of the enemy candidate.

Supplementing Becker's (1969) analysis with M. Douglas's (1966) account of cultural differences in enemyship, we hypothe- sized that enemyship will be an especially attractive means of compensating for control threats when the broader social system is perceived as disordered and incapable of providing protection from harm, whereas bolstering the perceived strength of the system will be the preferred response when the system appears ordered and secure. The results of Study 3 supported this hypothesis: Participants led to view the prevailing system as disordered responded to a control threat by viewing a personal enemy as responsible for negative occurrences in their lives and by denying the influence of random forces on negative occurrences. However, these participants were no more likely to attribute positive life events to a friend's influence. In contrast, and in line with Kay et al.'s (2008) findings, participants led to view the system as ordered responded to control threats by bolstering their belief in the system's order and strength.

Study 4 tested whether perceiving an enemy capable of causing diffuse harms would actually decrease perceived risk in the world and thereby bolster feelings of personal control. As predicted, control-threatened participants who were exposed to an ambiguously powerful enemy (but not one whose powers were explicitly known or who was weak) showed reduced perceptions of chaotic risk, which in turn bolstered perceptions of personal control.

Taken together, the current studies are the first to systematically examine the psychological function served by perceiving powerful enemies in the world, while additionally providing evidence of the psychological process by which enemies serve a controlrestorative function, and the situational conditions under which people are more likely to exaggerate an enemy's power and influence as a means of compensating for personal control concerns.

\section{Connections With Past Research}

It is important to integrate these studies with previous research and to understand the new questions and challenges they pose for future investigations. As mentioned in the introduction, some past research has suggested that enemies function at the group level as outgroup scapegoats, helping to maintain or enhance ingroup cohesion (Allport, 1954/1979; Silverstein, 1992). Consistent with this notion, history is flush with examples of leaders presenting their followers with enemies as a means of ameliorating internal divisions or of deflecting blame in the aftermath of some negative uncontrollable event (Cantril, 1941). There are some parallels between scapegoating and enemyship as currently defined. Both scapegoats and enemies, for example, are perceived as powerful (Glick, 2002) and can be either individual figures (as in the current Study 1), reviled outgroups (as in Study 4), or particular individuals who represent rival groups (Study 2). Furthermore, the results of Study 3 suggest that, like scapegoats, enemies are often ascribed influence when the strength of the broader system is undermined.

However, we believe that the current research highlights a psychological function of enemyship that is distinct from the group-level functions of scapegoating. The creation of a scapegoat is typically a post hoc effort to deflect responsibility for a particular event or condition by projecting it onto another group ( $\mathrm{T}$. Douglas, 1995). In contrast, focalizing influence onto an enemy in the manner we have described is a more forward-looking process designed to minimize perceptions of diffuse and chaotic risks in the world and is not directed at the interpretation of a particular 
event of importance to the group. More importantly, the current conceptualization views enemyship as serving control needs at the level of the individual, whereas scapegoating has largely been associated with group-level rather than individual-level motivational states. Thus, Studies 1 and 3 both focused on personal rather than group enemies, and all of the present studies focused on feelings of personal control, the influence of the enemy over one's own life, and the likelihood of events happening to oneself. In short, the present research has taken the existential perspective that enemyship partially fulfills the individual's need to cope with the realization that one's life and well-being are continually influenced by capricious forces. Although individual and collective, personal and political entities can equally serve enemyship or scapegoating roles, the current perspective on enemyship differs importantly from a scapegoating analysis in its consistent focus on the target's potential to restore control for the individual, rather than to reduce feelings of blame or explain past hardship for the group. Future scapegoating research might benefit by examining ways in which the individual's global concerns over chaotic risk, as compared to group concerns about a specific event, influence the scapegoating process.

Another line of relevant research has examined the need to attribute a human face to evil via the personification of sources of harm in the world (Shweder, Much, Mahapatra, \& Park, 1997). There is some evidence that people are more likely to personify target objects when they have a high desire for control (Epley, Waytz, \& Cacioppo, 2007). Thus, concerns with personal control appear to play a role in the tendency to personify sources of misfortune, as well as to attribute greater influence to enemies. However, the two strategies are conceptually and empirically distinct. Conceptually, personification is the imbuing of a single entity or phenomenon with humanlike characteristics; enemyship, in contrast, is a means of cognitively narrowing down the multifarious hazards in one's environment. Empirically, many of the current findings are difficult to explain as instances of personification. If participants in our studies were simply motivated to assign a human face to evil, then they would be expected to attribute exaggerated influence not only to an enemy but to any aversive other (Study 1) and to prefer (or at least see as an equally viable source of evil) an enemy whose characteristics were explicitly defined (Study 4). In contrast, and consistent with our current existential conceptualization, people compensated for decreases in perceived personal control across the studies by selectively ascribing influence to malicious, focal enemy figures, whose shadowy powers allowed them to be viewed as potentially responsible for diffuse external threats.

The reported cultural differences in enemyship (Adams, 2005) must also be addressed in light of the current research. Study 3, which focused on the perceived order or disorder of the prevailing system, offers one possible explanation for these cross-cultural differences. To the degree that people are more likely to ascribe power to enemy figures in response to personal control threats within a disordered system, people living in systems marked by high levels of disorder and salient uncontrollable risks should evidence a greater need to perceive powerful personal enemies. Therefore, it is possible that people living in West Africa tend to report having more enemies than their North American counterparts because they are more likely to habitually view themselves as living in a social system where interpersonal relationships (includ- ing enemyships) are more significant sources of personal control than broader institutional forces (see Adams, 2005, for discussion of interdependent self-construals amongst Ghanaians).

Of course, no system is capable of dealing with all potential threats, and even systems perceived to be highly capable are imperfect sources of order and security. In addition, confidence in a system's ability to deal with potential problems waxes and wanes over time in response to economic, political, and security challenges. Thus, whereas the need to attribute influence to an enemy may be elevated in systems characterized by high levels of disorder or under conditions of heightened system threat, explicit reminders of disorder are probably not necessary for enemy attributions to serve a control-maintenance function. We saw, for example, that participants in Studies 1, 2, and 4 attributed exaggerated influence to enemy figures even in the absence of a disordered system prime. People may simply seek powerful enemies in response to control threats unless they are presented with an ordered system prime (Study 3) or are allowed to bolster feelings of confidence in the capability of the current system. Consistent with Kay et al. (2008), individual differences in perceptions of system order and capability may also moderate the use of system- and enemy-bolstering control maintenance strategies.

\section{Directions for Future Research}

In addition to unifying prior findings and illuminating avenues for development of past research, we believe the present work has interesting broader social implications. For instance, these studies stand to shed light on modern preoccupations with media portrayals of serial killers and other public enemy figures that focus on their uncanny powers and larger-than-life prowess (Schmid, 2005). From our perspective, people turn to lionized enemies on their televisions as focal points for concerns over more diffuse sources of evil. Future studies might investigate the specific characteristics (e.g., cunning, ambiguity) with which people are motivated to imbue their enemies in response to a control threat.

In a similar vein, the current studies suggest the counterintuitive but important possibility that people will be motivated to create and/or perpetually maintain clear enemies to avoid psychological confrontations with an even more threatening chaotic environment. Another line of future research could investigate whether perceptions of personal control might actually decrease after participants are given an opportunity to vanquish or subdue an important enemy figure.

Nietzsche (1878/2002, p. 183) wrote that "He who lives by fighting with an enemy has an interest in the preservation of the enemy's life"; in light of the present studies, one might take this to imply that, at a broad level, society has a vested interest in maintaining clear enemy figures to serve as focal points for concerns with diffuse threat. Given current global concerns with economic and natural hazard, it is interesting to note that by declaring a "War on Terror," the U.S. government has highlighted a type of enemy that is both ambiguously powerful (Sellnow, Ulmer, Seeger, \& Veil, 2008) and in some sense immortal-for as long as terrorism of any kind exists, the country has an enemy. Indeed, as long as people are haunted by a sense of inadequacy in the midst of a random and impersonal world, they may never be able to eradicate personified evil from their personal lives and the 
political arena, for they may need their enemies more than they have heretofore realized.

\section{References}

Adams, G. (2005). The cultural grounding of personal relationship: Enemyship in North American and West African worlds. Journal of Personality and Social Psychology, 88, 948-968.

Aiken, L. S., \& West, S. G. (1991). Multiple regression: Testing and interpreting interactions. Newbury Park, CA: Sage.

Allport, G. W. (1979). The nature of prejudice. Cambridge, MA: Perseus Books. (Original work published in 1954)

Baumeister, R. F., \& Leary, M. R. (1995). The need to belong: Desire for interpersonal attachments as a fundamental human motivation. Psychological Bulletin, 117, 497-529.

Becker, E. (1969). Angel in armor. New York, NY: Free Press.

Brown, D. (2000). Contemporary nationalism: Civic, ethnocultural and multicultural politics. New York, NY: Routledge

Cantril, H. (1941). The psychology of social movements. New York, NY: Wiley.

Coxe, S., West, S. G., \& Aiken, L. S. (2009). The analysis of count data: A gentle introduction to Poisson regression and its alternatives. Journal of Personality Assessment, 91, 121-136.

Douglas, M. (1966). Purity and danger. Baltimore, MD: Penguin Books.

Douglas, T. (1995). Scapegoats: Transferring blame. New York, NY: Routledge.

Duttweiler, P. C. (1984). The Internal Control Index: A newly developed measure of locus of control. Educational and Psychological Measurement, 44, 209-221.

Epley, N., Waytz, A., \& Cacioppo, J. T. (2007). On seeing human: A three-factor theory of anthropomorphism. Psychological Review, 114, $864-886$

Fiske, S. T., Cuddy, A. J. C., Glick, P., \& Xu, J. (2002). A model of (often-mixed) stereotype content: Competence and warmth respectively follow from personal status and competition. Journal of Personality and Social Psychology, 82, 878-902.

Furnham, A., \& Steele, H. (1993). Measures of locus of control: A critique of children's, health and work-related locus of control questionnaires. British Journal of Psychology, 84, 443-479.

Glick, P. (2002). Sacrificial lambs dressed in wolves' clothing: Envious prejudice, ideology, and the scapegoating of Jews. In L. S. Newman \& R. Erber (Eds.), Understanding genocide (pp. 113-142). New York, NY: Oxford University Press.

Hans, T. A. (2000). A meta-analysis of the effects of adventure programming on locus of control. Journal of Contemporary Psychotherapy, 30, $33-60$.

Holt, R. R. (1989). College students' definitions and images of enemies. Journal of Social Issues, 45, 33-50.

Hutchful, E., \& Aning, K. (2006). The political economy of conflict. In A. Adekeye \& R. Ismail (Eds.), West Africa's security challenges: Building peace in a troubled region (pp. 195-223). Boulder, CO: Lynne Rienner.

Jarvis, B. G. (2004). MediaLab (Version 2004) [Computer software]. New York, NY: Empirisoft.

Kay, A. C., Gaucher, D., Napier, J. L., Callan, M. J., \& Laurin, K. (2008). God and the government: Testing a compensatory control mechanism for the support of external systems. Journal of Personality and Social Psychology, 95, 18-35.
Lau, G. P., Kay, A. C., \& Spencer, S. C. (2008). Loving those who justify inequality: The effect of system threat on attraction to women who embody sexist ideals. Psychological Science, 19, 20-21.

Lerner, J. S., \& Gonzalez, M. (2005). Forecasting one's future based on fleeting subjective experiences. Personality and Social Psychology Bulletin, 31, 454-466.

Nietzsche, F. W. (1980). Götzen-Dämmerung [Twilight of the idols]. Berlin, Germany: Walter de Gruyter. (Original work published in 1889)

Nietzsche, F. W. (2002). Human, all too human (R. J. Hollingdale, Trans.). Cambridge, England: Cambridge University Press. (Original work published in 1878)

Preacher, K. J., \& Hayes, A. F. (2008). Asymptotic and resampling strategies for assessing and comparing indirect effects in multiple mediator models. Behavior Research Methods, 40, 879-891.

Reich, J. W., \& Zautra, A. J. (1990). Dispositional control beliefs and the consequences of a control-enhancing intervention. Journal of Gerontology, 45, 46-51.

Schmid, D. (2005). Natural born celebrities: Serial killers in American culture. Chicago, IL: University of Chicago Press.

Sellnow, T. L., Ulmer, R. R., Seeger, M. W., \& Veil, S. R. (2008). Terrorism as chaos: A chaos model for managing random acts of terror. In D. O'Hair R. Health, \& G. Ledlow (Eds.), Terrorism: Communication and rhetorical perspectives (pp. 411-424). Cresskill, NJ: Hampton Press.

Shweder, R. A., Much, N. C., Mahapatra, M., \& Park, L. (1997). The "big three" of morality (autonomy, community, and divinity), and the "big three" explanations of suffering. In A. Brandt \& P. Rozin (Eds.), Morality and health (119-169). New York, NY: Routledge.

Silverstein, B. (1992). The psychology of enemy images. In S. Staub \& P. Green (Eds.), Psychology and social responsibility (pp. 145-164). New York, NY: New York University Press.

Thibaut, J. W., \& Kelley, H. H. (1986). The social psychology of groups. New Brunswick, NJ: Transaction Publishers.

Towery, M. (2008). Paranoid nation: The real story of the 2008 fight for the presidency. New York, NY: Hill Street Press.

Underwood, B., Froming, W. J., \& Moore, B. S. (1980). Mood and personality: A search for the causal relationship. Journal of Personality, $48,15-23$

Väjstfjäll, D., Peters, E., \& Slovic, P. (2008). Affect, risk perception and future optimism after the tsunami disaster. Judgment and Decision Making, 3, 64-72.

Watson, D., Clark, L. A., \& Tellegen, A. (1988). Development and validation of brief measures of positive and negative affect: The PANAS scales. Journal of Personality and Social Psychology, 54, 1063-1070.

Weinstein, N. D. (1980). Unrealistic optimism about future life events Journal of Personality and Social Psychology, 39, 806-820.

West, S. G., Aiken, L. S., \& Krull, J. L. (1996). Experimental personality designs: Analyzing categorical by continuous variable interactions. Journal of Personality, 64, 1-48.

Whitson, J. A., \& Galinsky, A. D. (2008, October 3). Lacking control increases illusory pattern perception. Science, 322, 115-117.

Wiseman, J. P. (1989, May). Friends and enemies: Are they opposites? Paper presented at the meeting of the International Network on Personal Relationships, Iowa City, IA.

Wiseman, J. P., \& Duck, S. (1995). Having and managing enemies: A very challenging relationship. In S. Duck \& J. T. Wood (Eds.), Confronting relationship challenges (pp. 43-72). Thousand Oaks, CA: Sage. 


\section{Appendix}

\section{Events Used in Enemy Attributions Measure (Study 3)}

\section{Negative Events}

Several files are mysteriously deleted from your desktop; you are seriously injured; you experience a terrible bout of food poisoning; on your most recent credit card statement, a strange purchase appears that you don't remember making; a stranger points in your direction, sneers, and whispers to someone as you're walking down the street; you have a particularly bad day; one day you can't find one of your more valued possessions (such as a favorite $\mathrm{CD}$ or article of clothing); you hear a strange noise late at night and don't know what's causing it.

\section{Positive Events}

You have a particularly good day; you are saved at the last minute from what you thought was going to be an awkward and frustrating social situation; driving in the morning, one of your favorite songs is played on a call-in radio program, and it brightens your day; you have been worried about a significant financial debt, but one day suddenly that debt is lifted from you; you receive a promotion at work or a good grade on an assignment without feeling like you have done anything to deserve it; you unexpectedly come into possession of some extra money; you suddenly hear some very good news; you are saved from serious injury.

\section{Neutral Events}

A single event influences your mood for the rest of the week; one day your whole outlook on the world and other people seems to change; you find yourself in a place you've never been before; you encounter an object, the sight of which fills you with a sudden, powerful emotion; you receive an unexpected phone call with personally important information; you receive and read an email which drastically alters your mood for the rest of the day; you unexpectedly bump into someone on the street; after this semester, you move into a new dorm room, apartment, or house.

Received April 27, 2009

Revision received August 19, 2009

Accepted August 19, 2009

\section{E-Mail Notification of Your Latest Issue Online!}

Would you like to know when the next issue of your favorite APA journal will be available online? This service is now available to you. Sign up at http://notify.apa.org/ and you will be notified by e-mail when issues of interest to you become available! 